\title{
Erratum: Learning without Coding
}

\author{
Samuel E. Moelius III ${ }^{1}$ and Sandra Zilles ${ }^{2}$ \\ 1 IDA Center for Computing Sciences \\ 17100 Science Drive, Bowie, MD 20715-4300 \\ semoeli@super.org \\ 2 Department of Computer Science \\ University of Regina \\ Regina, Saskatchewan, Canada S4S 0A2 \\ zilles@cs .uregina.ca
}

Our ALT'2010 paper claimed that every computably finitely thick LZ96, Definition 9] class of languages can be identified by enumeration operator [MZ10, Definition 1(e) and Theorem 12]. However, this is, in fact, false. We intend to include a proof of the claim's negation in the journal version of our paper, which has been submitted.

Acknowledgements. We would like to thank Sanjay Jain for noticing our error, and for providing us a proof of the claim's negation.

\section{References}

[LZ96] Lange, S., Zeugmann, T.: Incremental learning from positive data. Journal of Computer and System Sciences 53(1), 88-103 (1996)

[MZ10] Moelius, S., Zilles, S.: Learning without coding. In: Hutter, M., Stephan, F., Vovk, V., Zeugmann, T. (eds.) ALT 2010. LNCS(LNAI), vol. 6331, pp. 300-314. Springer, Heidelberg (2010) 